\title{
Formation of Potassium Nanostructures on Reconstructed High Index Si (5512)2x1 Surface for Night Vision Devices (NVD)
}

\author{
Awanish Kumar Sharma ${ }^{1}$, Manoj Dhiman ${ }^{2}$, Ram Kumar ${ }^{3}$, Sulaxna Sharma (Dr.) \\ 1, 2, 3 Department of Physics, Graphic Era University, Dehradun, India. \\ ${ }^{4}$ Assistant Professor, Department of Chemistry THDC, IHET, Tehri Uttaranchal
}

\begin{abstract}
In the present study potassium nanostructure was grown on the high index reconstructed $\mathrm{Si}$ (5512) $2 x 1$ surface due to their potential application in the night vision devices (NVD). The formation of potassium atoms $(K)$ on high index Si semiconductor under controlled kinetic and thermodynamic growth conditions having desired shape and size with low work function were studied. The studies have been performed on a reconstructed high index silicon surface at room temperature as well as on high substrate temperatures such as $\left(375,550\right.$ and $\left.680^{\circ} \mathrm{C}\right)$. The structural properties of the high index trenched template have been exploited for the development of desired nanostructures of different size and shape. It is constructed to a planner surface having a single domain with 1-D symmetry and relatively largest unit cell $(5.35 \mathrm{~nm})$. In the present study, growth of potassium nanostructures on the high index reconstructed Si $(55$ 12) surface occur, which can be potentially utilized in night vision devices. The experiments were performed in-situ in a Ultra high vacuum (UHV) system in-housed with various surface sensitive techniques such as Auger Electron Spectroscopy (AES), Electron Energy Loss Spectroscopy (EELS), and Low Energy Electron Diffraction (LEED).
\end{abstract}

Key Words: High index Si Surface, Potassium metal, Night Vision Device

\section{Introduction}

The exotic properties of nanomaterials showed the potential applications in the area of catalysis, sensors, optoelectronics, and many more. Surfaces and interfaces are crucial components of nanostructures, thereby establishing a bridge to more traditional surface science. Recent advancement in electronics and photonic devices are related to the directional growth of low-dimensional nanoscale structures and interface formation on various solid surfaces. A well-defined template is required for the growth of nanostructure of desired shape and size on a large scale and applies them to nanodevices of higher density [1]. There are large numbers of templates are available like $\mathrm{Si}, \mathrm{Ge}, \mathrm{ZnO}$, etc., but Silicon as a template is an obvious choice for the growth of epitaxial and self-assembled nanostructure due to its sustained scientific and technological interests. A lot of studies have been carried out of metal nanostructure and metal semiconductor interfaces which have potential application in delta dopped system, single electron tunneling, optoelectronic devices and other potential ULSI devices. By the control over several kinetic and thermodynamic factors such as flux rate, surface free energy, lattice mismatch, substrate reconstruction, substrate temperature of tailored metal nanostructures have been formed on various $\mathrm{Si}$ surfaces. One of the potential templates to satisfy such a goal is the high index $\mathrm{Si}$ (5512) surface. It is reconstructed to a planner surface having a single domain with 1-D symmetry and relatively largest unit cell $(5.35 \mathrm{~nm})$ [2]. Many studies have been already reported of the metal adsorption $(\mathrm{Ag}$, $\mathrm{Au}, \mathrm{Cu}, \mathrm{Bi}$ and $\mathrm{In}$ ) on high index $\mathrm{Si}$ (5512) surfaces and form the one dimensional nanostructure with large aspect ratio and study of various growth modes and formation of super-structures on Si (5512) surface [3-9]. Extensive studies of various metals like $\mathrm{Sb}$, In, $\mathrm{Ga}$, and $\mathrm{Na}$, nanostructures on low and high index $\mathrm{Si}$ have already been carried out [10].

For enhancing the quality, several low work function materials in image intensifier tube have been studied [11-13]. It has been found that alkali metals are promising material for this intention, as they are known for their low work function and high secondary electron emission. They also tarnish easily and have low melting points and densities. Because of these properties alkali metals have potential application in the area of low work function and negative electron affinity cathode, which can be used as image intensifier tubes in night vision devices. Control growth of multi-alkali structure is an important challenge for surface science. In addition, the alkali metal over layers on semiconductor surface has been a model system for understanding metalsemiconductor interfaces. The present study aims to grow alkali metal (K) nanostructure on the high index reconstructed Si (5512) surface under controlled kinetic and thermodynamic growth conditions. Nanostructure of desired shape and size with low work function thus formed will have application in night vision devices (NVD). 


\section{Experimental}

The experiments were performed in-situ in an UHV chamber with a base pressure of $2 \times 10^{-10}$ Torr, housed with a high precision sample manipulator, a retarding field analyser (RFA) with various surface sensitive techniques like Auger Electron Spectroscopy (AES), Electron Energy Loss Spectroscopy (EELS), and Low Energy Electron Diffraction (LEED). A sample of size $20 \times 8 \mathrm{~mm}^{2}$ is cut from p-type boron doped Si (5512) wafer having a resistivity of $10-15 \mathrm{ohm}-\mathrm{cm}$. The sample was cleaned by modified Shiraki process [14] after that it is mounted in to a precision manipulator with the Ta sample holder. The sample is degassed at $600^{\circ} \mathrm{C}$ by direct resistive heating for 12 hour followed by repeated flashing to $1150^{\circ} \mathrm{C}$ for 5 second and cooling to RT at a very slow rate of $2^{\circ} \mathrm{C} / \mathrm{s}$. [15]. The sample temperature is monitored by a $\mathrm{W}-\mathrm{Re}(5 \%$ and $25 \%)$ thermocouple mounted behind the sample, which is also calibrated with the help of an optical pyrometer. The atomic cleanliness of the sample was ascertained by the absence of carbon or other contaminations on the surface by AES, and the observation of characteristic sharp spots of $2 \times 1$ reconstruction in the LEED pattern of the $\mathrm{Si}$ (5512). Potassium (K) deposition was made from a tantalum-Knudsen cell, whose flux rate was controlled by regulating the current to the cell, and is measured in terms of the adsorbed monolayers. The monolayer is calibrated by measuring the $\mathrm{K} / \mathrm{Si}$ Auger ratio. Monitoring the Auger intensity ratio as a function of deposition time, uptake curve has been plotted which provides information about the growth mode of K on Si substrate. The Auger spectra and LEED pattern were digitally acquired and analyzed.

\section{Results and Discussion}

Adsorption of Potassium on $\mathrm{Si}(\mathbf{5 5 1 2})$ surface at Room Temperature

At room temperature (RT), potassium (K) is adsorbed on clean reconstructed $\mathrm{Si}$ (5512)2x1 surface. The Auger intensity ratio of adsorbate $\left(\mathrm{I}_{\mathrm{k}}\right)$ to substrate $\left(\mathrm{I}_{\mathrm{si}}\right)$, called as uptake curve, with deposition time is shown in Figure 1(a). The curve shows a linear increase in the intensity ratio up to 9 min of potassium deposition afterwards slop of intensity ratio changed which shows the completion of first potassium monolayer on $\mathrm{Si}(5512)$ substrate. The deposition of first monolayer in $9 \mathrm{~min}$ on $\mathrm{Si}$ (5512) revealed the flux rate of potassium atoms $0.11 \mathrm{ml} / \mathrm{min}$. The change in the slope is due to the attenuation of the $\mathrm{Si}$ signal by the atoms of $\mathrm{K}$ in second layer. On further deposition, the Auger intensity ratio increases linearly with deposition time up to 18 min. Further change in slope is observed at $18 \mathrm{~min}$ of deposition which suggest the completion of second potassium layer on $\mathrm{Si}$ (5512) substrate. The uptake curve shows that deposition of K on Si substrate follow the layer-by-layer growth mode i.e., Franke Vander Merve growth mode [16].

\subsection{Desorption of Potassium on Si (5512) at High Temperature}

The thermal stability of room temperature layer-by layer grown system is seen in above Fig. 1(b), which plots the Auger intensity ratio of K (LMM) at $252 \mathrm{eV}$ and $\mathrm{Si}(\mathrm{LVV})$ at $92 \mathrm{eV}$, as the RT adsorbed system is annealed to increasing temperatures. It is evident from the figure that at room temperature (RT), K/Si ratio is about 0.83 which is equal to the two monolayer plus islands. On annealing the substrate from RT to $225^{\circ} \mathrm{C}$, the islands which were formed on the top of two monolayers desorb due to thermal energy. As we further increase the substrate temperature beyond $225^{\circ} \mathrm{C}$ the Auger ratio remains constant i.e. 0.6 and it hardly changes up to temperature $375^{\circ} \mathrm{C}$. It means bilayer remains stable between the temperature $225^{\circ} \mathrm{C}$ to $375^{\circ} \mathrm{C}$, on further increasing the substrate temperature from $375^{\circ} \mathrm{C}$ to $500^{\circ} \mathrm{C}$ it sharply falls to ratio about $0.3(1 \mathrm{ML})$. On further increasing the substrate temperature, we observed that single monolayer remains stable between the temperatures $500^{\circ} \mathrm{C}$ to $600^{\circ} \mathrm{C}$. At temperatures greater than $600^{\circ} \mathrm{C}$ the Auger ratio further reduces and finally potassium (K) desorbs completely at $800^{\circ} \mathrm{C}$ from clean $\mathrm{Si}(5512)$ surface.
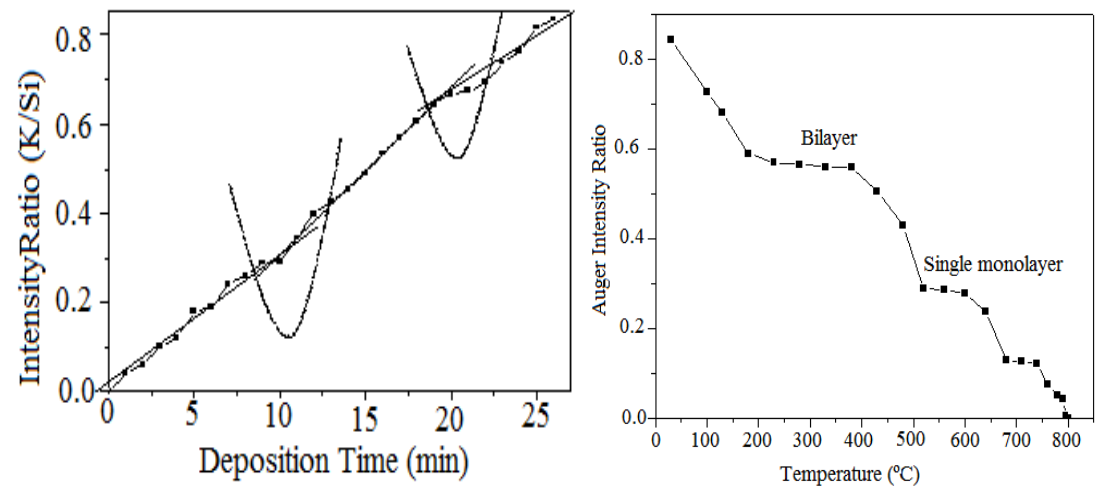

(a)

(b)

Figure.2: Auger Intensity ratio of potassium atoms on reconstructed $\mathrm{Si}$ (5512) 2x1 system (a) adsorption at room temperature and (b) desorption at high temperature. 
The sum of square of errors (SSQ) method has been adopted to calculate the break in the K/Si uptake curve which also confirms that break points occurs at deposition time 9 min and 18 min corresponding to completion of first and second monolayer. A schematic model diagram of the kinetically controlled \& thermodynamics stable growth of potassium atoms on reconstructed Si (5512) 2x1 system at room temperature are shown in Fig. 2.

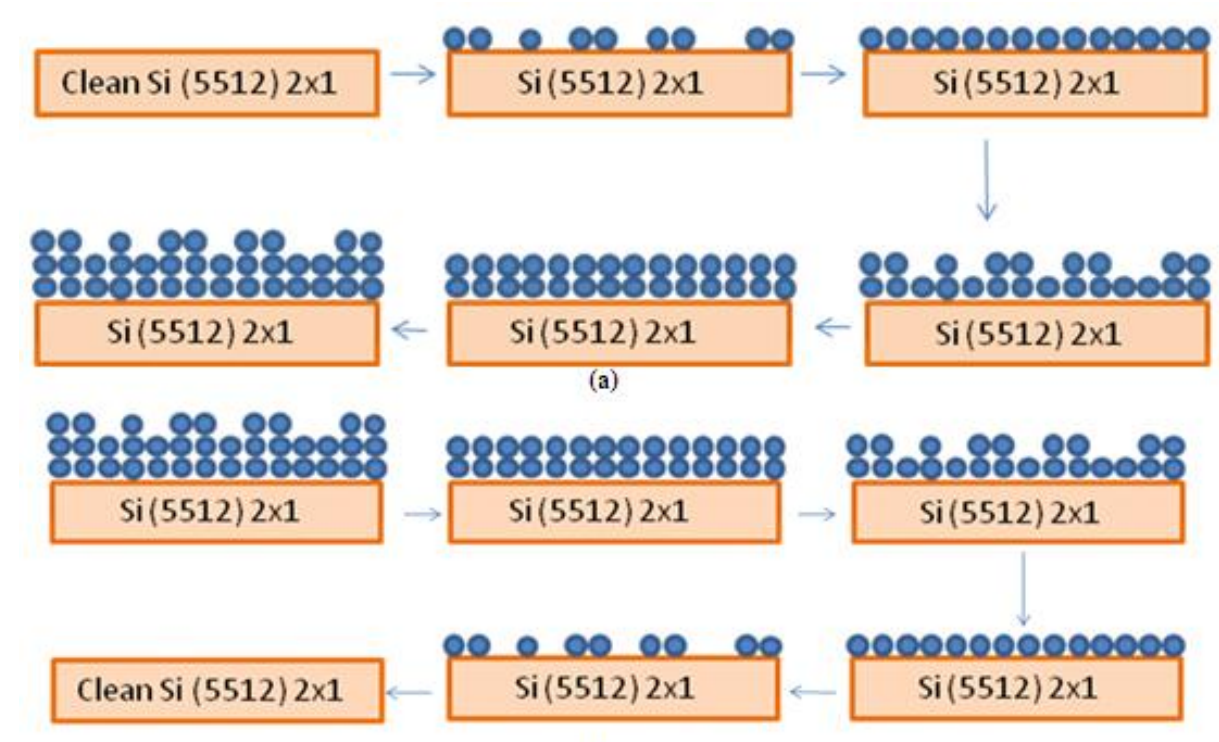

(b)

Fig.2: Schematic model diagram of Potassium atoms on reconstructed $\mathrm{Si}(\mathbf{5 5 1 2}) 2 x \mathrm{l}$ system at room temperature (a) controlled growth at room temperature and (b) desorption at high temperature.

\subsection{Adsorption of $\mathrm{K}$ on $\mathrm{Si}(5512)$ at $375^{\circ} \mathrm{C}$}

The clean reconstructed $\mathrm{Si}$ (5512) surface held at $375^{\circ} \mathrm{C}$ and $\mathrm{K}$ is allowed to adsorbed on Si surface to develop K/Si interface which is monitored by the Auger spectroscopy. The K uptake curve is shown in Fig.3(a), where the K (LMM) and Si (LVV) Auger signals are plotted as a function of deposition time. The curve shows a linear increase in the intensity ratio up to $9 \mathrm{~min}$ of deposition time, as observed at RT, after that there is a change in slope which confirmed that $1 \mathrm{ML}$ is completed on the clean Si (5512) surface. The deposition of first monolayer in $9 \mathrm{~min}$ on Si revealed that flux rate of potassium atoms on Si (5512) is $0.11 \mathrm{ml} / \mathrm{min}$. On further deposition of $\mathrm{K}$ on Si no break has been found till $20 \mathrm{~min}$ of deposition time as it was earlier observed at RT. This may be due to the change in interface energy caused by the annealing temperature. It means there are some islands which are formed on to the top of the monolayer. So we can say that there are layer plus island on the $\mathrm{Si}$ substrate which revealed that $\mathrm{S}$ - K growth mode [17] is present here.

\subsection{Desorption of $\mathrm{K}$ on $\mathrm{Si}$ (5512) at High Temperature}

The desorption studies of $\mathrm{K}$ on $\mathrm{Si}$ (5512) substrate held at temperature higher than $375^{\circ} \mathrm{C}$. The thermal stability of layer plus islands grown system is shown in Fig. 3(b), which plots the auger ratio of K (LMM) at $252 \mathrm{eV}$ and $\mathrm{Si}(\mathrm{LVV})$ at $92 \mathrm{eV}$ as a function of substrate temperature in ${ }^{\circ} \mathrm{C}$. This can be done by annealed the substrate for $1 \mathrm{~min}$ at different substrate temperature and measured the auger intensity ratio. The curve shows a linear decrease in the auger intensity ratio up to the temperature $550^{\circ} \mathrm{C}$ and this ratio almost remains same between the temperature 550 to $640^{\circ} \mathrm{C}$. It means single monolayer remains stable between this temperatures range because the thermal energy is less than the binding energy of $\mathrm{K}$ and $\mathrm{Si}$ atoms. At temperature greater than $640^{\circ} \mathrm{C}$ thermal energy overcomes the binding energy of $\mathrm{K}$ and $\mathrm{Si}$ atoms. As a result $\mathrm{K}$ atoms start desorbing from this monolayer smoothly and completely desorbs at $80^{\circ} \mathrm{C}$. 


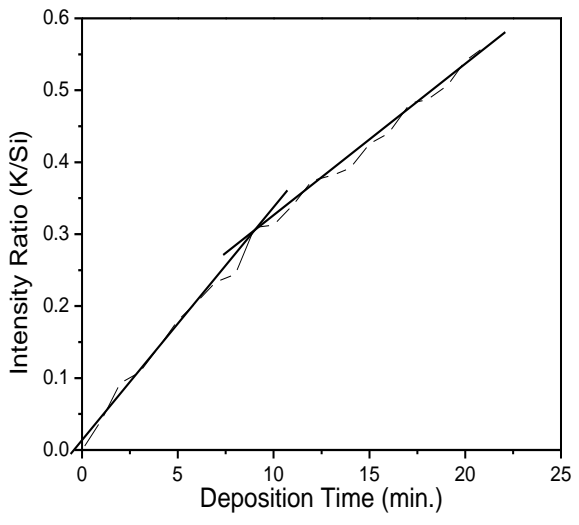

(a)

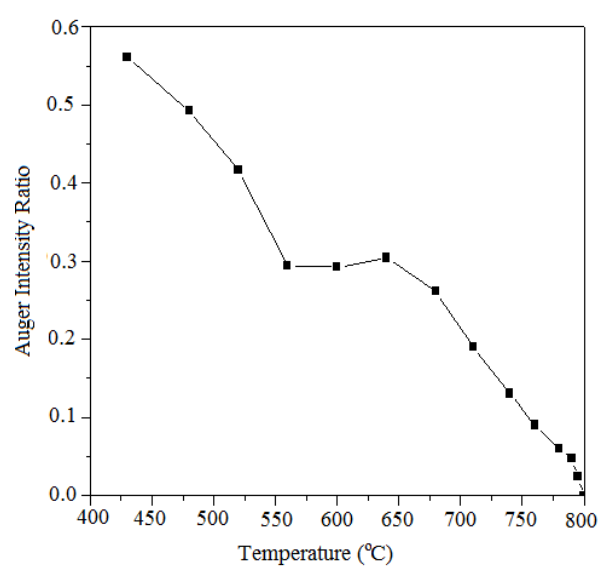

(b)

Fig. 3:. Auger Intensity ratio of K atoms on reconstructed Si (5 5 12)2x1 system for K (a) growth at 375

${ }^{\circ} \mathrm{C}$ and (b) desorption at high temperature.

The sum of square of errors (SSQ) method has been adopted to calculate the break in the K/Si uptake curve which also confirms that break points occurs at deposition time 9 min corresponding to completion of first monolayer. A schematic model diagram of the kinetically controlled \& thermodynamics stable growth of potassium atoms on reconstructed $\mathrm{Si}$ (5512) 2x1 system at high temperature has been shown in Fig. 4(a and b).

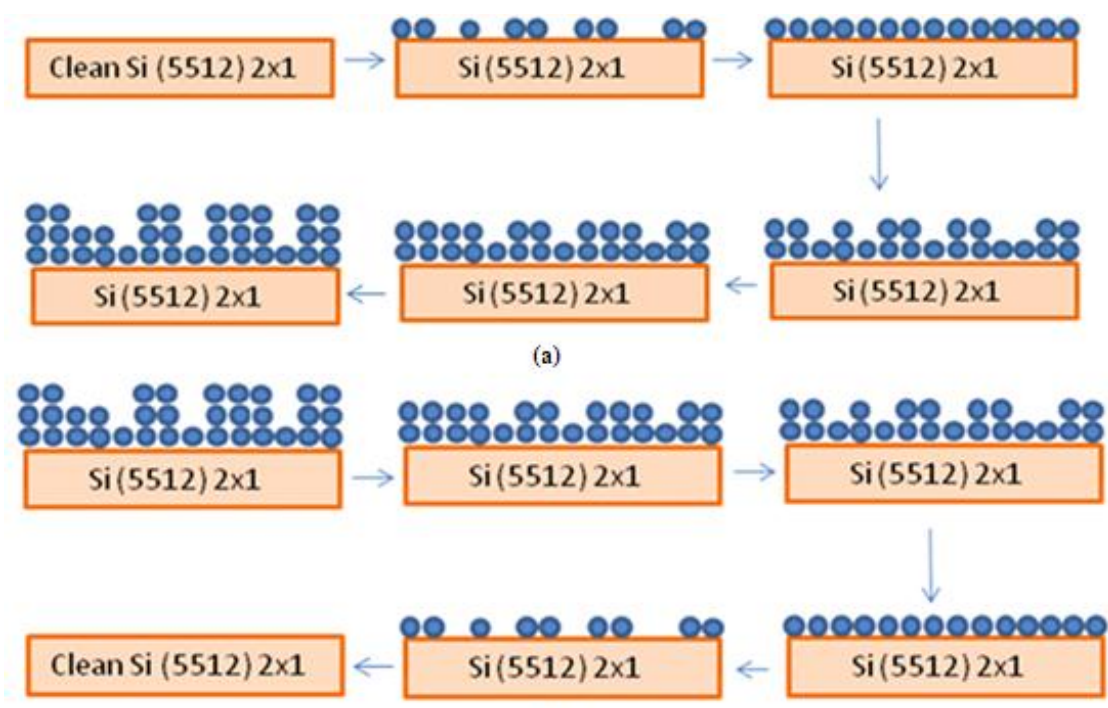

(b)

Fig. 4: Schematic model diagram for Potassium atoms on reconstructed Si (5512) 2xl system (a) adsorption at $375^{\circ} \mathrm{C}$ and (b) desorption at high temperature.

\subsection{Adsorption of $\mathrm{K}$ on $\mathrm{Si}(5512)$ at $550^{\circ} \mathrm{C}$}

At $550^{\circ} \mathrm{C}$ potassium is adsorbed on clean reconstructed $\mathrm{Si}$ (5512) $2 \times 1$ surface and the Auger intensity ratio K/Si with deposition time is plotted in Fig. 5(a). From the curve it is evident that potassium deposited on hot substrate $\left(\right.$ at $550^{\circ} \mathrm{C}$ ) in a very less amount in comparison with substrate which is held at $375^{\circ} \mathrm{C}$. It clearly indicates that there is no monolayer is forming at this temperature, only islands are formed, so it followed the Volmer- Weber (V-W) growth mode [18]. The auger ratio increases linearly up to the deposition time of $18 \mathrm{~min}$ with a ratio of 0.2 after the further deposition of $\mathrm{K}$ atoms on hot $\mathrm{Si}$ substrate we observed uptake curve is almost saturated between the deposition time from $18 \mathrm{~min}$. to $22 \mathrm{~min}$. This clearly implies that no more $\mathrm{K}$ atoms are allowed to deposit on to the hot substrate.

\subsection{Desorption of $\mathrm{K}$ on $\mathrm{Si}$ (5512) at High Temperature}

The thermal stability of islands grown system is shown in above Fig. 5(b) which plots the Auger ratio of $\mathrm{K}(\mathrm{LMM})$ at $252 \mathrm{eV}$ and $\mathrm{Si}(\mathrm{LVV})$ at $92 \mathrm{eV}$ as a function of substrate temperature in ${ }^{\circ} \mathrm{C}$. This can be done by annealed the substrate for $1 \mathrm{~min}$ at different substrate temperature and measured the auger intensity ratio. The curve shows a rapidly decrease in the Auger intensity ratio up to the temperature $740^{\circ} \mathrm{C}$ where the auger ratio is 
0.04. Further increasing the substrate temperature greater than the $740^{\circ} \mathrm{C}$ we observed that auger ratio drops but not in the same way as it happens earlier. As we go higher temperature greater than the $740^{\circ} \mathrm{C}$ we observed that curve goes smoothly. Finally K atoms completely desorbs from the substrate at $800^{\circ} \mathrm{C}$.

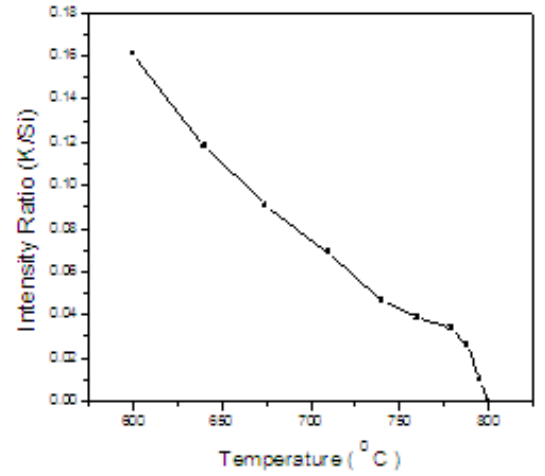

(a)

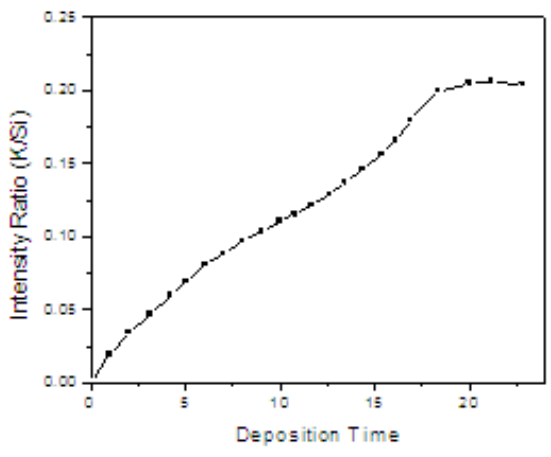

(b)

Fig. 5: Auger Intensity ratio of $\mathrm{K}$ atoms on reconstructed $\mathrm{Si}(5512) 2 \mathrm{xl}$ system for $\mathrm{K}$ (a) growth at $550^{\circ} \mathrm{C}$ and (b) desorption.

\subsection{Adsorption of $\mathrm{K}$ on $\mathrm{Si}(5512)$ at $680^{\circ} \mathrm{C}$}

Potassium is adsorbed on clean reconstructed $\mathrm{Si}(5512) 2 \mathrm{x} 1$ surface at $680^{\circ} \mathrm{C}$. The auger intensity ratio $\mathrm{K} / \mathrm{Si}$ with deposition time is plotted in Fig. From the curve it is evident that Potassium deposited on hot substrate $\left(\right.$ at $680^{\circ} \mathrm{C}$ ) in a very low coverage. It clearly indicates that there is no monolayer is forming at this temperature, only small islands are formed, so it followed the Volmer- Weber (V-W) growth mode [18]. Up to 6 min of deposition the auger ratio is too low, it is only 0.06 , but after the further more deposition of $\mathrm{K}$ on hot $\mathrm{Si}$ substrate we observed the saturation in up take curve which tells that no more $\mathrm{K}$ atoms is now deposited on to the hot $\mathrm{Si}$ substrate.

\subsection{Desorption of $\mathrm{K}$ on $\mathrm{Si}$ (5512) at High Temperature}

The thermal stability of islands grown system is shown in above figure which plots the auger ratio of $\mathrm{K}$ (LMM) at $252 \mathrm{eV}$ and $\mathrm{Si}(\mathrm{LVV})$ at $92 \mathrm{eV}$ as a function of substrate temperature in ${ }^{\circ} \mathrm{C}$. This can be done by annealed the substrate for $1 \mathrm{~min}$. at different substrate temperature and measured the auger intensity ratio. The curve shows a rapidly decrease in the auger intensity ratio up to the temperature $740^{\circ} \mathrm{C}$ where the auger ratio is 0.028 . Further increasing the substrate temperature greater than the $740^{\circ} \mathrm{C}$ we observed that auger ratio almost remains same. As we go for higher temperature greater than the $740^{\circ} \mathrm{C}$ we observed that the auger ratio decreases rapidly. Finally $\mathrm{K}$ atoms completely desorbs from the substrate at $800^{\circ} \mathrm{C}$.
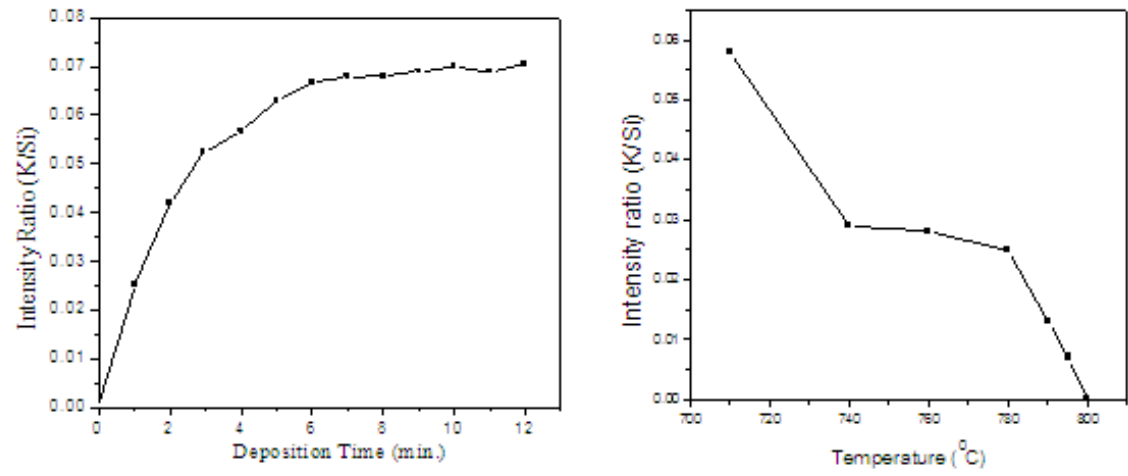

(a)

(b)

Fig. 6: Auger Intensity ratio of $\mathrm{K}$ atoms on reconstructed $\mathrm{Si}\left(55 \mathrm{j}\right.$ 12)2xl system for $\mathrm{K}$ (a) growth at $680^{\circ} \mathrm{C}$ and (b) desorption at high temperature. 


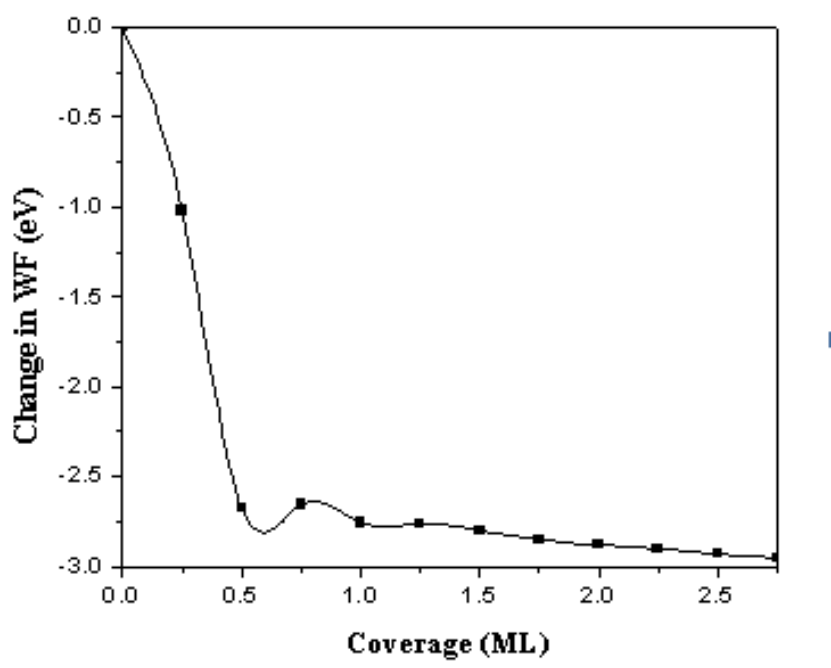

Fig. 7: Work function measurements on Potassium adsorbed on Si (5512) surface

The change in work function (WF) for K adsorbed on Si (5512) has been carried out by employing the UHV Kelvin Probe (KP) system. We assume that WF of substrate as reference and calculated the change in work function after $\mathrm{K}$ adsorption. The figure 7 plots the change in work function with the coverage of $\mathrm{K}$ in $\mathrm{ML}$ on $\mathrm{Si}$ (5512).it is evident from the curve that when the $1 / 4 \mathrm{ML}$ is adsorbed on $\mathrm{Si}$ (5512) surface, work function decreases by $-1.0 \mathrm{eV}$ from its initial value. As we further adsorb $\mathrm{K}$ on Si surface the WF changes rapidly with the coverage and it is $-2.75 \mathrm{eV}$ for the coverage of $1 / 2 \mathrm{ML}$. After $1 / 2$ adsorption there is no significant change observed in work function. The work function slowly decreases up to $-2.95 \mathrm{eV}$ for the coverage of $2.7 \mathrm{ML}$ of $\mathrm{K}$ on $\mathrm{Si}$ substrate. We observed that change in work function of $\mathrm{K}$ at $2.7 \mathrm{ML}$ is $2.95 \mathrm{eV}$. Adsorption of $\mathrm{K}$ on $\mathrm{Si}$ (100) was studied and it was found that WF decreases rapidly by value $-3 \mathrm{eV}$ up to coverage of $0.5 \mathrm{ML}$. In the present study we observed the same rapid change in WF but the value is slightly less than the obtained by S. Yu. Davydov et.al. The difference in these values may be due to either change in surface morphology or due to the presence of carbon as the form of contamination on Si (5512) surface.

\subsection{Low Energy Electron Diffraction (LEED) Analysis}

In order to establish a structural correlation between various super structural phases on Si $(55$ 12) surface, we have obtained the LEED patterns and along [665] direction as shown in Figs 8 below for the adsorption of $\mathrm{K}$ at various coverage and substrate temperatures. The LEED pattern obtained for the cleaned $\mathrm{Si}$ ( 55 12) - (2×1) surface is shown in Fig 7. The LEED pattern manifests the large unit cell of $0.768 \times 5.35 \mathrm{~nm}$ of $(2 \times 1)$ reconstructed $\mathrm{Si}(5512)$ surface. As $0.2 \mathrm{ML}$ of $\mathrm{K}$ is adsorbed on to the substrate held at room temperature, some of the LEED spots start weakening (Fig. 8) whereas others remain relatively intense, but when the coverage was increased to $0.5 \mathrm{ML}$ the weak LEED pattern transformed to an ordered structure, having 15 equally spaced spots along [665] direction. This shows the formation of a $(2 \times 225)$ phase. Further adsorption of $\mathrm{K}$ gives diffused fractional LEED spots. During desorption, we slowly annealed the K adsorbed (2.7ML) system and acquired LEED images. We could not observe any LEED spots up to the substrate temperature $500^{\circ} \mathrm{c}$ or up to coverage $>1 \mathrm{ML}$. For temperature between $\left(500-600^{\circ} \mathrm{c}\right)$, where the coverage remains stable (1ML), we observed the LEED spots which are different during growth. 12 LEED spots are observed along [665] direction, however spacing between the spots was not equal. This revealed that the observed LEED spots are formed due to the combination of more than one super structural phase. We calculate the distance between each spots and identified that observed 12 LEED spots belong to a mixed phase $(225+337)$. it suggests that $\mathrm{K}$ atoms rearrange themselves at higher temperature and form $(225+337)$ phase, where the width of unit cell is found to $3.7 \mathrm{~nm}$. Further increasing the annealing temperature $\left(700-750^{\circ} \mathrm{c}\right)$ the $\mathrm{K}$ induced LEED spots are observed ( 2 bulk spots +5 spots between bulk spots), again the spacing between spots were different. We analyzed the spacing and conclude that the structure formed on K/Si (5512) surface at $0.4 \mathrm{ML},\left(700{ }^{\circ} \mathrm{c}\right)$ is a combination of $(337+113)$ super structural phase. The unit cell size of $(337+113)$ super structure is $2.23 \mathrm{~nm}$ at coverage of $0.4 \mathrm{ML}$. 


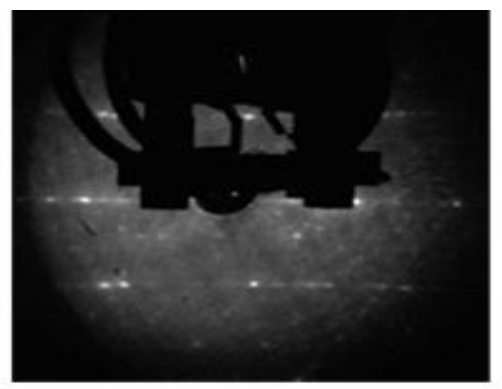

(a) 5512

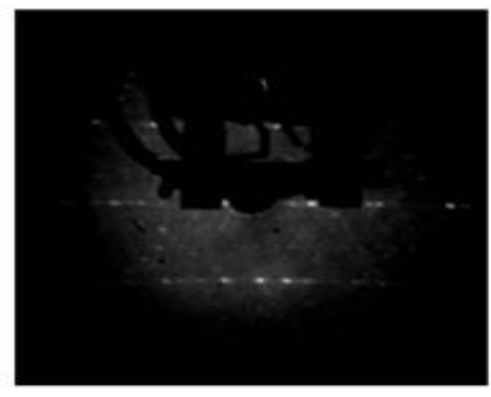

(c) $225+337$

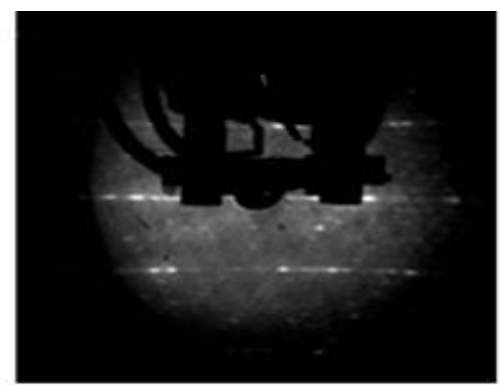

(b) $2 \times 225$

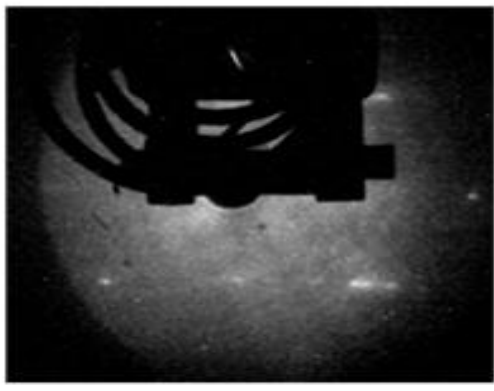

(d) $337+113$

Fig. 8: Low Energy electron diffraction Pattern

\section{Conclusions}

The adsorption of $\mathrm{K}$ on the high index $\mathrm{Si}\left(\begin{array}{l}5 \\ 5\end{array}\right.$ 12) at various temperatures demonstrates the role of kinetically driven phase formations on this highly trenched surface. At RT deposition of K on Si substrate follow the layer by layer growth mode (Frank-Vander Merwe growth). At HT $\left(375^{\circ} \mathrm{c}\right)$, it follow the layer plus islands growth mode (Stranski-Krastanov growth). At HT $\left(550^{\circ} \mathrm{c}\right)$, it follow the island growth mode (VolmerWeber growth). At HT $\left(680^{\circ} \mathrm{c}\right)$, it follow the island growth mode (Volmer-Weber growth). The measurement of WF has been performed during growth and change in the WF is calculated. When $1 / 4 \mathrm{ML}$ of $\mathrm{K}$ atoms are adsorbed on Si surface, the WF decreases by $-1.0 \mathrm{eV}$ from its initial values. On further deposition of $\mathrm{K}$ atoms on $\mathrm{Si}$ surface, the WF changes rapidly up to the value $-2.75 \mathrm{eV}$ for coverage of $1 / 2 \mathrm{ML}$. The WF slowly decreases up to $-2.95 \mathrm{eV}$ for the coverage of $2.7 \mathrm{ML}$.

We obtained the LEED patterns during adsorption and desorption of $\mathrm{K}$ on $\mathrm{Si}$ at various coverage and substrate temperature. At $0.5 \mathrm{ML}$ coverage, we got 15 equally spaced spots which characterize the formation of $(2 \times 225)$ phase i.e. $0.5 \mathrm{ML}$ coverage $\mathrm{K}$ grows and form nanostructure of width $4.4 \mathrm{~nm}$. During desorption at coverage $1 \mathrm{ML}\left(500-600^{\circ} \mathrm{c}\right)$, we observed the formation of $(225+337)$ super structural phase (width of unit cell $=3.7 \mathrm{~nm})$. During desorption at coverage $0.4 \mathrm{ML}\left(700-750^{\circ} \mathrm{c}\right)$, we observed the formation of $(337+113)$ super structural phase (width of unit cell $=2.23 \mathrm{~nm}$ ). The LEED pattern clearly indicates the formation of $\mathrm{K}$ induced nanostructures of desired sizes and shapes by controlling the kinetic and thermodynamic factors like flux rate and substrate temperature.

\section{Acknowledgment}

The authors are thankful of professor Govind and Kiyani for providing lab facilities at Surface Physics and Nanostructures Group, National Physical Laboratory, New Delhi, India.

\section{References}

[1]. M. K. Govind, V. K. Palival, S.M. Shivaprasad; Vacuum 82 (2008) 1452-1456.

[2]. H.H. Song, K.M. Jones, A.A. Baski; J. Vac. Sci. Technol. A 1696 (1999)171.

[3]. J. N. Crain, A. Kirakosian, K. N. Altmann, C. Bromberger, S. C. Erwin, J. L. Mcchesney, J. -L. Lin, F. J. Himpsel; Phys. Rev. Lett. 90 (2003) 176805.

[4]. S.R. Blankenship, H.H. Song, A.A. Baski, J.A. Carlisle; J. Vac Sci Technol A 1615 (1999) 17.

[5]. J.W. Dickinson, J.C. Moore, A.A. Baaski; Surf. Sci.561 (2004)193.

[6]. J.R. Ahn, H.W. Yeom, E.S. Cho, C.Y. Park; Phys. Rev. B 69 (2004) 233311.

[7]. S.S. Lee, N.D. Kim, C.G. Hwang, H.J. Song, J.W. Chung; Phys. Rev. B 66 (2002) 115317.

[8]. P.H. Woodworth, J.C. Moore, A.A. Baski; J. Vac. Sci. Technol. A 21 (2003) 1332.

[9]. S. Cho, J.M. Seo; Surf. Sci.565 (2004) 14.

[10]. A. Einstein; Ann. Physik. 17 (1905) 132.

[11]. D.K. Lim, D. Lee, H. Lee, S.-S. Bae, J. Choi, S. Kim, C. Ji, R. Rangan, D.A.A. Ohlberg, Y.A. Chang and R.S. Williams; Nanotechnology 18 (2007) 095706 and references therein. 
Formation of Potassium Nanostructures on Reconstructed High Index Si (5512)2xl Surface for ...

[12]. H. Bruining; "Physics and application of secondary electron emission", McGraw Hill Book Co., London (1954).

[13]. "Photomultiplier Handbook", Burle Technologies, Inc., New York (1989).

[14]. G. Boishin and L. Surnev; Surf. Sci. 273 (1992) 301.

[15]. H. Daimon and S. Ino; Surf. Sci. 164 (1985) 320.

[16]. M.J.J. Jack, and J.W.M Franken; Surface Science, 457 (2000) 295.

[17]. K. H. Kuo, Structural Chemistry 13 (2002) 221.

[18]. A. Zangwill; Physics at surfaces Cambridge University, Press, 1988. 